\title{
Fisioterapia na melhora da qualidade de vida no idoso institucionalizado
}

\author{
Carlla Henchen \\ Alessandra Fontana \\ Caroline Reimann \\ Dâmaris Rigotti \\ Leticia Giacomin \\ Josiane Schadeck Almeida Altemar
}

CADERNO DE RESUMOS

FisiSenectus. Unochapecó Ano 1 - Edição especial - 2013 p. 130

Carlla Henchen, acadêmica do $6^{\circ}$ período de Fisioterapia da Universidade Comunitária da Região de Chapecó (Unochapecó), carllaandreia@unochapeco.edu.br

\section{Resumo}

Introdução: Segundo a Organização Mundial da Saúde, a pessoa é considerada idosa a partir dos 65 anos. Desde então, ocorrem várias mudanças como comprometimento na memória, diminuição da força muscular, redução da água corporal e diminuição da amplitude de movimento. A fisioterapia exerce um papel importante no que diz respeito à interação social, promoção do envelhecimento saudável, a manutenção da capacidade funcional, prevenção de enfermidades e melhora da qualidade de vida. A Unochapecó tem assegurado uma formação generalista aos bacharéis de fisioterapia aptos a atuarem na atenção integral a saúde, oportunizando ao acadêmico práticas em ambientes da comunidade trazendo a aproximação com a realidade profissional. Objetivos: Realizar estratégias de promoção da saúde em idosos institucionalizados visando à melhoria na qualidade de vida. Metodologia: Este estudo consiste em um relato de experiência com um grupo de 13 idosos moradores do Centro de Convivência do Idoso CL Aurino Mantovani, sendo realizadas nove intervenções com duração de uma hora. As atividades foram baseadas em exercícios de coordenação motora, memória, equilíbrio, dinâmicas em grupo e alongamentos. 0 registro das atividades foi realizado a partir do diário de campo que era redigido todo dia após as intervenções e a análise deu-se por meio do conteúdo planejado pelas acadêmicas responsável pela intervenção. Resultados: No decorrer das intervenções percebeu-se a melhora da qualidade de vida e bem-estar físico dos envolvidos por meio do instrumento observacional aprimorando a convivência entres os mesmos. As intervenções desenvolvidas tiveram um papel importante para um envelhecimento saudável, evitando outras patologias e até mesmo que o idoso fique acamado. Considerações finais: Conclui-se que houve interação entre os agentes pertencentes ao cenário, grande aceitação proporcionando aos idosos uma melhora na qualidade de vida. A fisioterapia exerce um papel importante, desenvolvendo atividades e estratégias para recuperem a capacidade funcional, a autonomia, exercendo de forma independente suas funções na sociedade e a minimização da dependência nas atividades de vida diária.

\section{Palavras-chave}

Envelhecimento. Fisioterapia. Qualidade de vida. 